\section{World wide news and comment}

\section{TURKEY: TAX EQUALISATION THWARTS ROLL-YOUR-OWN DODGE}

Turkey, where a tobacco company recently introduced roll-your-own (RYO) cigarette kits, has taken the only sensible step open to a responsible government faced with such an attempt to hold onto smokers through exploiting tax differentials to reduce the price of smoking materials. It has simply equalised tobacco tax across all types of tobacco. European Tobacco, a Turkish tobacco company based in Mersin, in the south of the country, recently introduced a range of components, including a small hand-operated device, empty paper tubes and loose tobacco, for smokers to make cigarettes that can closely resemble those made in a factory. The attraction is that they cost much less due to the tax on loose tobacco previously being only about half of that on manufactured cigarettes.

The Turkish move came after a team from WHO met officials from Turkey's ministries of health and finance, together with the head of the country's parliamentary health commission.

A device similar to Mersin's was introduced by Imperial Tobacco in the UK in April 2011 (see July 2011 issue). ${ }^{1}$ A more elaborate system to exploit a similar tax differential appeared a few months later in Jamaica, involving electrically powered machines operated by smokers themselves in convenience stores and other shops where the machines are installed (see November 2011 issue). ${ }^{2}$ So far, however, neither the British nor the Jamaican government has announced any adjustments to tobacco taxes to close off the price advantages of the products.

The Turkish and British machines require a measure of work by their users, as well as possibly delivering finished products that may feel inferior to regular factory-made cigarettes. Thus, their sales potential may be limited, though diseases contracted by people who might otherwise quit or cut down smoking for economic reasons will be no less debilitating or fatal. However, the potential of

All articles written by David Simpson unless otherwise attributed. Ideas and items for News Analysis should be sent to: David.Simpson@ctsu.ox.ac.uk tax and price to influence consumption in all countries, already one of the most important public health tools available to governments, is likely to become ever more crucial as other measures bite. Turkey's lead in making the obvious adjustment to equalise tax across all types of tobacco is to be warmly applauded and, it must be hoped, followed by other countries.

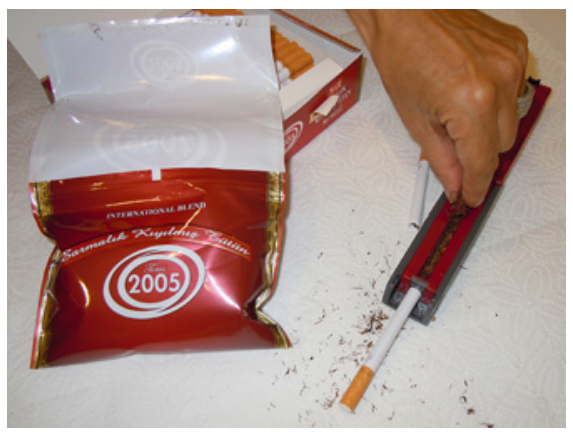

Turkey: a 'roll-your-own' (RYO) cigarette being made. The slot in the hand-operated device is filled with loose tobacco, ready to be pushed into a paper tube, with filter, fitted to the end of the slot. Turkey has now equalised tax on all tobacco products, ending the tax advantage being exploited by the introduction of RYO kits.

\section{USA: NIH BODY ISSUES GUIDANCE ON TOBACCO FUNDING}

For the first time among any of the US National Institutes of Health (NIH), the National Institute on Drug Abuse (NIDA) has issued guidance on tobacco industry research funding. NIDA, the federal research organisation focusing on drug abuse and addiction, included points for consideration by those in receipt of grants and those who may apply for them while also in receipt of tobacco industry funding. The guidelines were developed by the National Advisory Council on Drug Abuse, a high-level body which advises NIDA on research priorities and policy and provides a secondary level of review for applications under consideration for federal funding.

NIDA pulls no punches about the industry and the incompatibility of tobacco funding with publicly funded scientific research. In a background section explaining the rationale for its policy, for example, it cites a federal court finding in 2006 that the cigarette industry had engaged in wilful racketeering and conspiracy to conceal the dangers of smoking from the American public by improperly suppressing and terminating scientific research and destroying research documents. It further relates how this ruling was upheld in 2009 by the US Court of Appeals and how in 2010 the US Supreme Court denied the tobacco industry's appeal for further review of the ruling. In the final opinion in that case, NIDA recounts, the presiding judge ruled that nine cigarette manufacturers and two tobacco-related trade organisations had violated the Racketeer Influenced and Corrupt Organizations Act by engaging in a lengthy, unlawful conspiracy to deceive the American public about the health effects of smoking and environmental tobacco smoke, the addictiveness of nicotine, the lack of health benefits from lowtar and 'light' cigarettes, and manipulation of the design and composition of cigarettes to create and sustain nicotine addiction.

Against such a charge sheet of criminal activity, worthy of a Hollywood blockbuster about extreme corporate wrongdoing, it is hard to imagine on what grounds any politicians or other objectors to the NIDA policy could base their case. In the circumstances, NIDA's recommendations are comparatively mild. In a section listing points to consider, it reminds grantees how tobacco funding may compromise the credibility of their research and is viewed by many as aiding the industry's interests and thus harmful to public health and how it could damage the public's trust in NIDA-funded research.

In a section on research grant applicants who are also supported by tobacco funding, NIDA says it has to consider whether a grantee's funding relationship with the industry, including the potential use of its name in conjunction with that of one or more tobacco companies, may affect the credibility of the research results, as well as public confidence in NIDA's stewardship of its funds and its research-based recommendations.

NIDA makes clear that it bases research funding decisions on scientific merit and public health goals and that grantees receiving NIDA funds should consider the impact on NIDA's credibility and reputation within the scientific community. It remains to be seen whether, and if so how, anyone could do other than applaud the new policy. Indeed, many may feel it is a long overdue step towards ending the corrosive impact of tobacco industry funding on genuine, independent scientific research once and for all.

\section{GREECE: CONSUMPTION DOWN AT LAST}

Greece holds the unfortunate record of having as the world's highest documented 
cigarette consumption per capita, for which it is paying an extremely high price as tobacco attributable rates of death and disease are soaring. Government and private healthcare expenditures are estimated to exceed $€ 20$ billion (US\$27 billion) annually, an estimated 6\%-15\% of which are attributable to smoking, the nation's largest cause of preventable disease and death. Taking into account the needless suffering and the dire economic situation of Greece at present, such a price in human terms, as well as in expenditures for treating the morbidity of tobacco use, is clearly unacceptable.

To battle this behemoth, Greece launched an intensive tobacco control project in 2009. Called the HEART project-Hellenic Action for Research Against Tobacco-it is a collaborative effort between the ministries of health and education, the Hellenic Cancer Society and the Harvard School of Public Health. It aims to reduce smoking through increases in cigarette price through tobacco tax rises, clean indoor air laws, school education and media campaigns.

To date, and for the first time for more than 30 years, there has been a reduction in smoking prevalence over the two years to April 2011 of $4.7 \%$ overall, with a reduction in prevalence mainly among medium smokers $(-2.3 \%)$ and heavy smokers $(-2 \%)$. This decline in prevalence has also finally led to a decline in per capita cigarette consumption of $16 \%$ over the same two years. Regarding exposure to secondhand smoke in public places, research has indicated that despite enforcement problems, exposure in public places has been reduced by $35 \%$ since the enactment of smoke-free legislation in bars, cafés and restaurants. The smoke-free legislation is supported by the majority $(69 \%)$ of the Greek population, which has extended its support for smoke-free places to private homes, as over the past twoyears the percentage of smoke-free households in Greece has almost doubled.

These reductions in cigarette consumption and secondhand smoke exposure have been achieved without the use of enforcement mechanisms or strong media campaigns, suggesting that tough enforcement and media expenditure could lead to an even stronger outcome.

The current economic crisis and austerity measures in Greece pose an opportunity for strengthening tobacco control and reducing consumption. Specifically, the current tobacco control campaign has also had positive economic effects, including an influx over the past year of $€ 346$ million (US\$465 million) in additional tax revenue. Furthermore, the reduction in prevalence by $4.7 \%$ and per capita cigarette consumption by $16 \%$ has led to additional savings of $€ 150$ million (US\$200 million). These estimates should encourage other countries in dire economic situations to employ tobacco control, including taxation, as crucial levers to simultaneously promote public health and economic development. International economic organisations, led by the World Bank, the International Monetary Fund and the World Trade Organization, should aggressively pursue programmes and policies in step with WHO's Framework Convention on Tobacco Control, which champion the economic benefits of tobacco control.

\section{CONSTANTINE I VARDAVAS \& PANAGIOTIS} BEHRAKIS

Committee for Tobacco Control, Ministry of Health and Social Solidarity, Athens, Greece vardavas@hsph.harvard.edu.

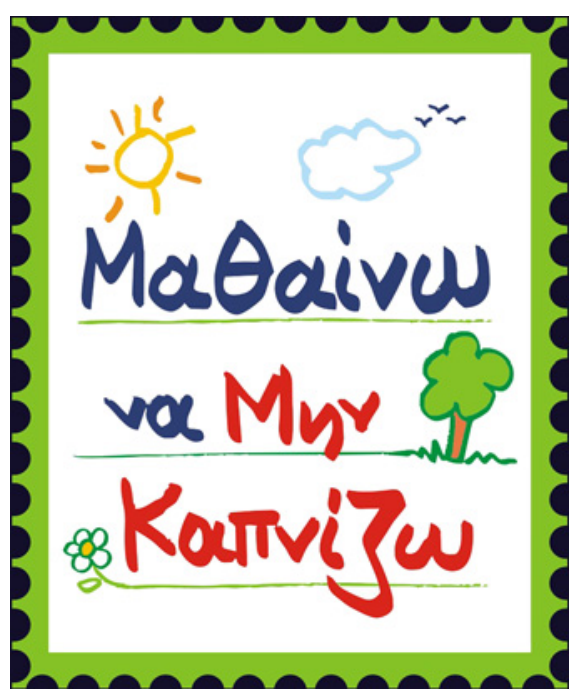

Greece: the logo of the tobacco control plan. The slogan translates as, 'I learn not to smoke'. The Greek word for 'learn' has a deeper meaning, conveying the idea of absorbing and digesting, as appropriate for both prevention and cessation.

\section{BANGLADESH: HUNDREDS RALLY FOR 12TH ANNIVERSARY}

In October, the Bangladesh Anti-Tobacco Alliance (BATA) celebrated 12 years of activity and a great deal of progress in one of the world's least affluent countries, where the British American Tobacco (BAT) once had more or less free reign to promote its products. In Bangladesh, high male smoking rates have been shown to exact a significant impact on household budgets, on top of their heavy toll of disease and healthcare costs.

Ironically, BATA could be said to owe its existence to its near namesake, as it was founded to unite a number of nongovernmental organisations (NGOs) to fight off a particularly irresponsible and arrogant marketing ploy. BAT, which had bought the controlling interest in the local tobacco monopoly, had chartered an ocean racing yacht to sail from Tower Bridge, London (the nearest suitable port to BAT's headquarters at the time), to Chittagong, Bangladesh, via stops in intermediate ports in 17 countries, all planned to be the focus for promotional media exposure, particularly in association with activities that appealed to the youth of each nation.

The yacht, named John Player Gold Leaf to promote BAT's international cigarette brand at every mention, was billed as undertaking a 'Voyage of Discovery'. Probably the only discovery intended by BAT was how much free publicity could be generated to associate its cigarettes with the healthy, exciting, tough image of oceangoing yachtsmen and their vessel. What it actually discovered was that decent people in low-income countries were simply not going to tolerate such blatant exploitation of their young people by the world's second largest tobacco company.

First, in Sri Lanka, a massive outcry, with street demonstrations and well-publicised calls for the boat to be impounded, resulted in an unexplained change of plan: instead of putting in to the southern port of Galle as scheduled, it stayed at sea, turning north-east for Bangladesh, where prearrival publicity was already under way (see March 2000 issue). ${ }^{3}$ But health advocates in Bangladesh, too, were incensed at steadily growing publicity in news media, spawned by BAT's press releases and augmented by paid advertisements. As these reached near-saturation level on billboards, in newspapers and at points of sale of tobacco, outrage among health and social welfare groups reached a critical mass, and some 15 organisations came together to protest against it. Thus, BATA was launched, a coalition of health, antidrug, tobacco control and women's groups. Legal challenges were launched against what BAT was doing, and the ill-advised tobacco voyage ended almost as ignominiously as if the boat had been holed below the waterline (see June 2000 issue). ${ }^{4}$

Since then, BATA has grown in strength and membership to a remarkable size. Events to mark the 12th anniversary included a meeting of more than 500 


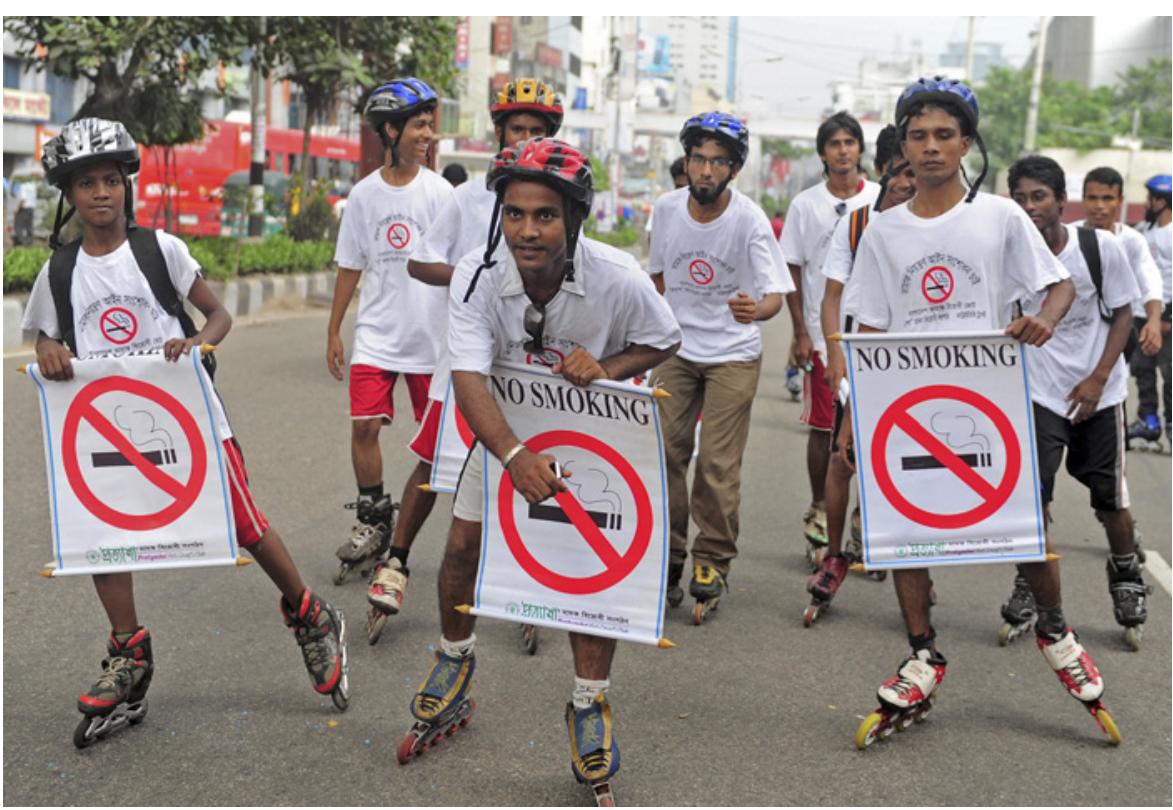

Bangladesh: health advocates on roller-blade skates in one of many rallies and demonstrations celebrating the country's first National No Tobacco Day and the 12th anniversary of the foundation of BATA, the alliance of NGOs working against tobacco. Photo: Firoz Ahmed.

NGOs in September and the country's first National No Tobacco Day, held on 9 October, the exact anniversary of the alliance's formation. A demonstration was held in front of the national assembly in Dhaka by more than 700 representatives of BATA network organisations. WBB ('Work for a Better Bangladesh') Trust, the secretariat for the alliance, distributed 15000 posters, 250000 leaflets and 50000 stickers to affiliated organisations for use on the day. In Dhaka, the information minister spoke of the need for comprehensive action and mooted the end to smoking scenes in televised drama, in view of its influence on young people.

Awards were presented to the commissioner of Dhaka police force, for making the police headquarters smoke free and to Shykh Seraj, a well-known media personality and head of the news department at the national broadcasting company's Channel 1, for making an eight-part report on the impacts of tobacco cultivation, among other work on tobacco. The state minister of health and family welfare announced that the government would be amending the country's tobacco law to incorporate provision for pictorial health warnings on all tobacco products. Bangladesh is already a Party to WHO's Framework Convention on Tobacco Control.

Around the country, local NGOs celebrated National No Tobacco Day through a variety of events: rallies, seminars, sticker campaigns, leaflet campaigns, poster displays and fairs. In Dhaka, a skating rally attracted much attention and all the events were covered widely throughout the country by both print and electronic media.

The story of tobacco control in Bangladesh offers an encouraging example to any country, whatever the size of its population, its economic wealth or the nature of its tobacco problem. It will probably never be known whether any quiet reflection has taken place in the boardroom of BAT, about just what a bad decision it was to sponsor the ill-fated Voyage of Discovery, and how, even in preFCTC days, it led to the creation of one of the world's most impressive coalitions of agencies fighting against tobacco.

\section{SPAIN: PEOPLE PREFER SMOKE-FREE BARS}

During the many years it took to make Spain's public places smoke-free, tobacco industry opposition was centred, as so often, on dire predictions that hospitality industry venues, especially Spain's numerous small tapas bars, would go out of business if there was nowhere that people could smoke in public. After a temporary industry victory allowing some businesses to designate smoking areas, Spain even had to endure the infamy of being cited by the tobacco industry as a model country (see January 2011 issue). ${ }^{5}$
How gratifying, then, that with the smoke-free goal eventually attained, research shows that far from putting off customers to hospitality venues, the ban has actually encouraged them to go out more. In a survey carried out by the Spanish society for family and community medicine, $70 \%$ of respondents said they went out to bars and restaurants as often as they did before the ban and $18 \%$ said they went out more. Only 12\% said they went out less. Perhaps most reassuring of all was that half the smokers surveyed said they would be against going back to allowing smoking in bars and restaurants. Has this research and the true story of the 'Spanish model' been mentioned by tobacco companies and their apologists as they furiously lobby in countries that still have to implement a comprehensive public places ban? Of course not! Like every new piece of evidence showing the harmfulness of its products, it is something the tobacco industry feels is best kept as quiet as possible as it continues to pursues its overriding quest to maintain business as usual.

\section{AUSTRALIA: SMOKING BANS IN CARS WITH CHILDREN}

Australia's leadership in tobacco control moved a step further recently when the Australian Capital Territory (ACT-the small state comprising the federal capital, Canberra) passed a law banning smoking in cars carrying children. The states of New South Wales, Western Australia and South Australia all have similar laws. An adult caught smoking in a motor vehicle in ACT when children aged under 16 years are also in the vehicle will face an on-the-spot fine of A $\$ 250$ (US\$265) or a fine of up to $A \$ 5500$ (US\$5825) if the offence goes to court. The government recently launched a campaign, set to run for six months, to educate the public about the dangers of smoking in cars with children and about the new law, which will come into force in 2012.

\section{EUROPE: TOBACCO-FREE EURO 2012 FOOTBALL TOURNAMENT}

More bad news for the international tobacco industry, as another hefty dent is made in the social acceptability of smoking and its association with popular sport. The Union of European Football Associations is to enforce a complete ban on the use, sale or promotion of tobacco in all stadia involved in the Union of European Football Associations EURO 2012 football tournament, to be played in June and July 2012. The regulation will apply without exception to all spaces within the 
perimeter of every stadium in which the football (soccer) tournament matches take place, both indoors and outdoors. The tobacco-free policy was developed and will be implemented in collaboration with WHO, the World Heart Federation, the European Healthy Stadia Network, local organising committees in the host countries, Poland and Ukraine, and local health advocacy groups.

Androulla Vassiliou, the European Commissioner responsible for sport, pointed out the potential wider impact of the move. "EURO 2012 will be a magnet for millions of spectators and fans, so this sends a powerful message", she said. "In addition, a tobacco-free EURO 2012 sets the standard for other sporting events across the continent."

\section{WORLD/PHILIPPINES: TOUGH WORDS FROM WHO CHIEF}

The director-general of WHO has urged governments to unite against 'Big Tobacco', accusing the industry of dirty tricks, bullying and immorality in its attempts to keep people smoking. Dr Margaret Chan accused tobacco firms of using lawsuits to try to subvert national laws and international conventions aimed at curbing cigarette sales. "It is horrific to think that an industry known for its dirty tricks and dirty laundry could be allowed to trump what is clearly in the public's best interests," she said at a WHO meeting in Manila, the Philippine capital in October 2011.

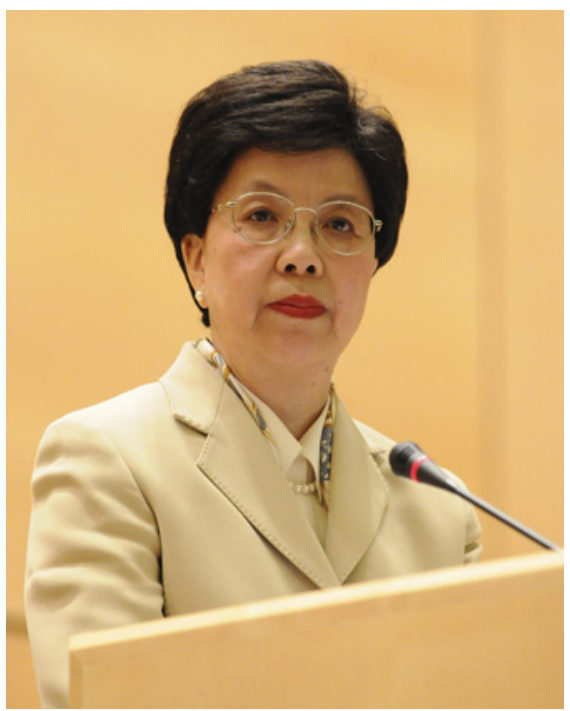

World/Philippines: WHO Director-General Dr Margaret Chan.
Dr Chan cited legal action by the tobacco industry against anti-smoking measures in Australia and Uruguay, saying these were 'scare tactics' intended to frighten other countries from following suit. "It is hard for any country to bear the financial burden of this kind of litigation, but most especially so for small countries," she said. "Big tobacco can afford to hire the best lawyers and [public relations] firms that money can buy. Big money can speak louder than any moral, ethical or public health argument and can trample even the most damning scientific evidence... I urge all these countries to stand firm together; do not bow to pressure; we must never allow the tobacco industry to get the upper hand," she said.

\section{RUSSIA: JTI 'GLAMOUR' CIGARETTES SPONSOR MOSCOW FASHION WEEK}

Glamour cigarettes, owned by Japan Tobacco International, was once again an official sponsor of the 2011 Volvo Moscow fashion week. In 2010, Glamour set up an elaborate stage, with pink curtain backdrops and luxurious chairs, to help staff collect names and hand out cigarettebranded promotional items to fashion week patrons. According to news reports at the time, Glamour arranged for a backdrop and photographers so that people in its lounge felt like models. Attractive Glamour cigarette girls handed out pink Glamour cigarette promotional items to people willing to give them personal contact details and other information for the company's database. Russian health advocates noted the inappropriateness of linking smoking with glamour and fashion in a country with such a massive burden of ill health caused by tobacco.

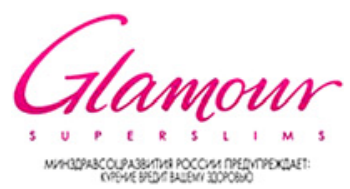

USA: JUDGE BLOCKS GRAPHIC WARNINGS The Food and Drug Administration (FDA) and the public health community recently received further evidence of how effective the tobacco industry believes graphic health warnings will be on cigarette packs, when tobacco companies took legal action to try to prevent the FDA imposing them in the USA.

The FDA has demanded that tobacco manufacturers place stronger warnings and graphic pictures on the upper half of cigarette packs, starting in September 2012 , in place of the current text-only warnings on the sides of cigarette packs. Five tobacco companies, including Reynolds American Inc and Lorillard Inc, have sued the FDA in the US District Court for the District of Columbia, arguing that the graphic images violate the free speech clause of the US Constitution's First Amendment. The companies have indicated that they would accept stronger text warnings instead.

During the hearing, the tobacco companies asked a judge to temporarily block the implementation of the graphic warning labels while the case proceeds about whether the graphics are legal. Industry lawyers argued that the companies would soon have to start spending "tens of millions of dollars" to purchase and test new equipment capable of printing the new labels (this despite the fact that many of these same companies produce cigarettes for sale in other countries that have long required such labels).

At the end of November, US district judge Richard Leon sided with the manufacturers and granted them a temporary injunction blocking the warnings requirement. He confirmed that their challenge was likely to succeed, as implementing the new warnings would compel speech in violation of the First Amendment, which prohibits any law being made that restricts basic rights, including the freedom of speech. Within days, the Obama administration filed an appeal against the judge's ruling.

Tobacco Control 2012;21:2-5.

doi:10.1136/tobaccocontrol-2011-050330

\section{REFERENCES}

1. Simpson D. UK/World: Imperial's low-tax cigarette device. Tob Control 2011;20:254.

2. Simpson D. Jamaica: government fiddles while tobacco burns. Tob Control 2011;20:394.

3. Simpson D. Asia: choppy seas for BAT butt boat. Tob Control 2000;9:9

4. Simpson D. Bangladesh: voyage of disdain sunk without trace. Tob Control 2000;9:130.

5. Simpson D. Spain: beyond the 'Spanish model' to a total ban. Tob Control 2011;20:6. 